\title{
Spatial Heterogeneity and Its Determinants of Taiwan Firms in Mainland China
}

\section{Yingbo Li}

School of Public Policy and Management, Tsinghua University, Beijing, China.

Email: liyingbo@tsinghua.edu.cn

Received October $17^{\text {th }}, 2012$; revised November $19^{\text {th }}, 2012$; accepted December $21^{\text {st }}, 2012$

\begin{abstract}
Taiwan investment in Mainland China over the last 20 years has shown uneven distribution characteristics in the eastern, central and western regions. What factors led to this type of investment pattern? Did this characteristic continue or change after ECFA? Based on statistical data and the investment conditions, this paper used Moran's I index analysis method to measure the heterogeneity of the spatial distribution of Taiwan investment in Mainland China over 20 years. Then the study applied ordinary and spatial panel analyses to discuss impacting factors of nearly three years of Taiwan investment in Mainland China. The outcome shows that Taiwan investment in Mainland China had a double-fixed timing effect and special effect during the last three years, which impacted Taiwan investment in different regions. Finally, this study proposed the regional strategy choices of the Taiwan invested enterprise in Mainland China in the future at four levels.
\end{abstract}

Keywords: Taiwan Firms; Spatial Heterogeneity; FDI; Panel Data

\section{Introduction}

Over the past 20 years, cross-strait trade and offshore investment of Taiwan firms in Mainland China have bloomed rapidly. With the improvement of economic infrastructure and situations of China, the pattern and mechanism of industrial cooperation for cross-strait have changed a lot. As of 2010, there were 83,133 Taiwaninvested projects in Mainland China, and the actual use of Taiwan investment reached US\$52.02 billion. The domains of investment have shifted from down-stream manufacturing to up-stream manufacturing and modern services as well as from labor-intensive industries and capital-intensive industries to technology-intensive industries and knowledge intensive industries.

The investment has also shifted from one-way, onetime investment to continuous large-scale investment. The industrial operation style is changing from OEM (Original Equipment Manufacturer) to ODM (Original Design Manufacturer) and OBM (Own Branding \& Manufacturing). According to Taiwan's economic data, as of January 2011, there were 112 invested projects, with investment amounts reaching US\$137 million. The spatial distribution of Taiwan firms expanded from the northern and western parts to the southern and eastern parts of Mainland China. However, the investment pattern over the last 20 years did not seem to change significantly before the assignment of Economic cooperation and Framework Agreement (ECFA). Conversely, the ECFA has promoted the close economic collaboration between Mainland China and Taiwan. Doses it will cause the change of factors impacting Taiwan enterprises' investment in Mainland China? The paper will discuss that issue along with the comparison between factors of Taiwan enterprises' investment before and after ECFA. The paper is organized as follows. Section 2 is literature review. Section 3 discusses the overall pattern of Taiwan investment in Mainland China. Section 4 uses Moran' I index to evaluate the spatial agglomeration and then adopt panel data to assess the impacting factors influencing Taiwan firms' location in the Mainland China. Section 5 is conclusions and policy implications.

\section{Literature Review}

Based on location theory such as Weber's industrial location and Thünen's agricultural theory, factors such as market capacity, labor cost, transportation cost, and the relative technology level proposed by Alibe, Hirsch and Vermon have empirically explored the cost-driven FDI mode. In recent years, factors such as tariffs, non-tariff barriers, tax policy, language, culture and environment have also bloomed in the mainstream of investment theory. Second, the perspective of agglomeration economies can be applied to study the motivation and purpose of FDI, and these discussions are mainly based on aspects 
such as the scale of the economy, specialization, supply chain integrity, and learning by doing. Third, Dunning's eclectic theory has been used to describe the regional advantage. Dunning mainly emphasizes the balanced judgment of the host country, ownership advantages and internalization advantages as the real motivation for FDI. In recent years, the study of Taiwan investment in Mainland China reflects three features. First, macro retrospective analysis emphasizes the summarized experiences and goals of Taiwan investment over 20 years. Zou Xiao Juan (2005) systematically reviewed the characteristics of several phases of Taiwan investments in Mainland China and gave a predictive analysis of future investment [1]. Yu Mei Ci (2008) indicated that there was a significant promotion of Taiwan investment in employment in Mainland China during the period from 19962000, but it was not significant during the period 20012006 [2]. Nie Ping Xiang (2009) discussed the changes in Taiwan investment in Mainland China after the global financial crisis at the national macro level and at the level of the micro-enterprise and proposed a developmental strategy for Taiwan investment in Mainland China [3]. Yan An (2011) summarized the participation of Taiwan entrepreneurs in the reformation, opening, modernization and construction phases of development and pointed out that Taiwan investment activities provided the infrastructure for the initial establishment of cross-strait relations and peaceful development [4].

Another concern is the location analysis of investment in the mainland. As Duan Xiao Mei (2006) pointed out, northern China is the new hot spot for Taiwan investment. She proposed a strategy to improve the investment environment in Mainland China with respect to aspects such as legal and financial considerations as well as intellectual property, infrastructure, and medical services [5]. Dai Shu Geng and Dai Ping Sheng (2008) used spatial analysis to measure the space of 53 cities and 31 provinces in Mainland China as well as autonomous regions that receive investments from Taiwan [6]. Studies have shown that the area in Mainland China that receives investments from Taiwan has significant spatial aggregation characteristics. Wang Zhi and Wang Yu Xin (2009) found that with the economic and market expansion in Mainland China, Taiwan-invested enterprise through regional headquarters, $R$ \& D centers and localization strategies resulted in business integration, thereby enhancing profitability [7]. Hu Shao Dong (2010) stated that the degree of perfection of the regulatory regime and the regulatory environment has a significant positive impact on Taiwan investment [8]. Dai Shu Geng and Ceng Wei Han (2011) applied a DEA-Tobit-related model to analyze eight provinces in Mainland China that receive investment from Taiwan [9]. The authors investigated trade cooperation performance with Taiwan and its causes dur- ing the period 1994-2008. The overall technical efficiency was not high; the characteristics of the population, traffic conditions, the level of technological integration and other factors significantly affected the cross-strait economic and trade cooperation with respect to regional economic performance.

The third focus is the study of the development of Taiwan investment in Mainland China by evaluating the differences between regions or industries that receive investment from Taiwan, such as the Yangtze River Delta [10], Jiang Su [11], Fujian [12], Xia Me [13] and Shenzhen [14]. Wang You Li and Wang Jian (2010) pointed out that Taiwan investment in Mainland China occurs in different stages as the main axis and is characterized by significant regional differences in the industrial layout [15]. Factors that affected the shift in the focus of Taiwan investment in Mainland China including hard environments, such as the geographic location, and institutional factors such as policy portfolios, the level of productive force development, the transfer of industrial chain linkage cluster effects and the drive of the industrial chain. Duan Xiao Mei and Zhang Zong Yi (2011) reported a dynamical interactive relationship between Taiwan investment and the trade between two coasts, but the effect of Taiwan investment was more significant for trade in Taiwan [16].

Based on the above literature, it is clear that Taiwan investment in Mainland China cannot be described by a simple explanation of the investment situation. Instead, the development of Taiwan investment in Mainland China is continuously changing. This subject has prompted investigation into topics such as traceability of the theory, the development of research methods and public policy to carefully observe and explore the trajectory, and the motivation and future trends in the development of Taiwan investment in Mainland China. Simultaneously, scholars have considered the development of the new era of Taiwan investment in Mainland China from a global perspective, considering the high degree of technological innovation and the new regionalism, which will also require follow-up study.

\section{The Overall Development of Taiwan Investment in Mainland China}

According to the data from 2010 Environment and Risk Survey of Regional investment in Mainland China of Taiwan Electrical and Electronic Manufacturers Association report (hereinafter referred to as the TEEMA report), in 2010, Taiwan entrepreneurs evaluated the investment environment in Mainland China based on the certain major advantages in terms of infrastructure, local approval of Taiwan businesses, regional economic development and preferences of local governmental sections, 
as opposed to the disadvantages in terms of common market, R \& D alliance, investigation and punishment of poor-quality goods, funding the upgrading of Taiwan businesses and gaining local human capital. Thus, the current Taiwan investment mainly focused on hardware infrastructure, and the investment environment of the software facilities remains unsatisfying. The fact also reflects the declining driving factors of the current Taiwan investment cost and the formation of an environment-oriented investment model. From the perspective of regional distribution, eastern and northern China remains dominant regions for investment, but central and southwestern China have recently become investment hot spots.

Figure 1 illustrates that eastern and southern China (Hubei and Hunan, Guangdong, Guangxi, Hainan and Henan Provinces) are the most hotspot regions of Taiwan investment.

From an investment impact point of view, Taiwan preferences are well connected with the geographic environment, the available infrastructure, the economic environment and the business environment. Subsequently, these factors have become the dominant factors in Taiwan investment policy (see Figure 2).

In general, the main reasons for FDI enterprises, including market-driven foreign competitiveness, cost-driven production sharing factors, and the complete construction supply, are connected to the progressive formation of industry clusters. National and international academic studies have been conducted on the regional distribution decision factors of FDI from different viewpoints, including the market capacity, the degree of aggregation, labor costs, infrastructure, human capital, industrial structure, the level of openness, the level of market orientation, and the presence of incentives (Zhang Yan Bo, 2008).

In Mainland China, because of the significant intercountry differences in customs and language [16], foreign corporate investors have greater risk than do Taiwan investors; therefore, the investment strategy of many foreign manufacturers is a location-based strategy, that is, to select a heavily invested region (such as Shanghai or Beijing) to reduce risk [17]. The pattern of Taiwan investment in Mainland China is primarily based on utilizing regional advantages and business features [18]. Because experience is also an important factor for business location [19], the first Taiwan investors, who were unfamiliar with the business environment in Mainland China, favored investments in special economic regions or shared areas of Taiwan and foreign business to share the economic externalities. Now Taiwan entrepreneurs became more and more familiar with its legal and institutional environment and accumulated more social capital, expanding the investment beyond the coastal economic open zones (according to Figure 3). Some large enterprises began to monitor or enter Mainland China in a limited way to develop a new market space and discover new developmental opportunities.

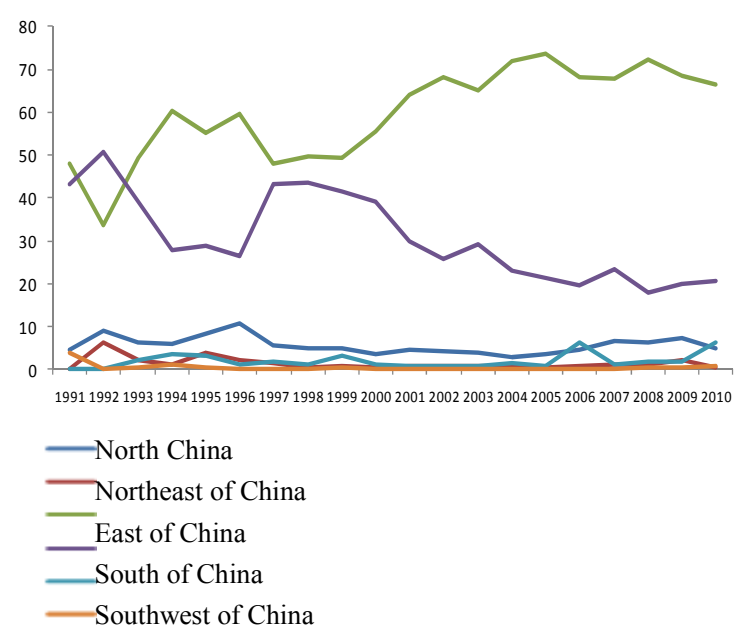

Figure 1. The regional distribution of Taiwan investment in Mainland China (1991-2010). Source: Investment Commission, Taiwan Ministry of Economic Affairs, "Monthly Bulletin of Overseas Chinese and Foreign Investment Statistics 2010 (12)".

\section{Weakness}

\begin{abstract}
Local professional and technical talent natural environment suitable for business development local communication infrastructure degree of approval from the public and local government Informationization requirements
\end{abstract}

Degree of local government assistance to actively upgrade Taiwanese business Strength of local government actively investigating shoddy and dangerous goods Local government support for development of cross-straits joint business Government support for cross-straits joint business entering international markets Local government actively improves foreign business investment environment Strength

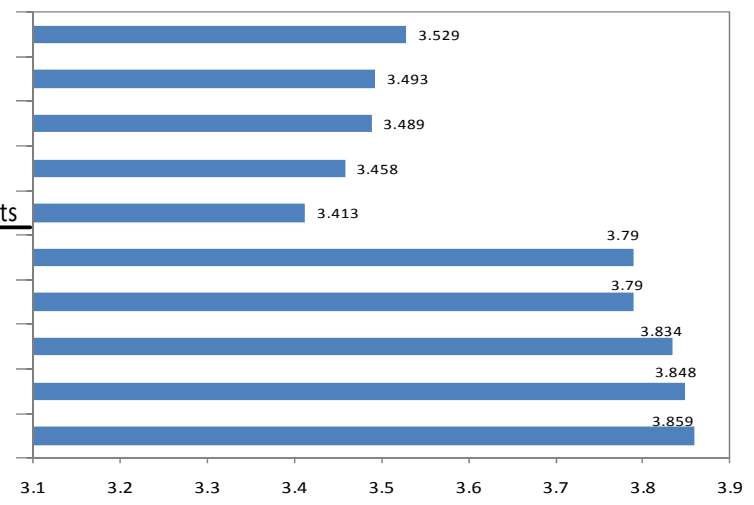

Figure 2. Assessment of the strengths and weaknesses of the Chinese environment with respect to Taiwan investment, Source: Comprehensive analysis based on the data from the TEEMA report. 


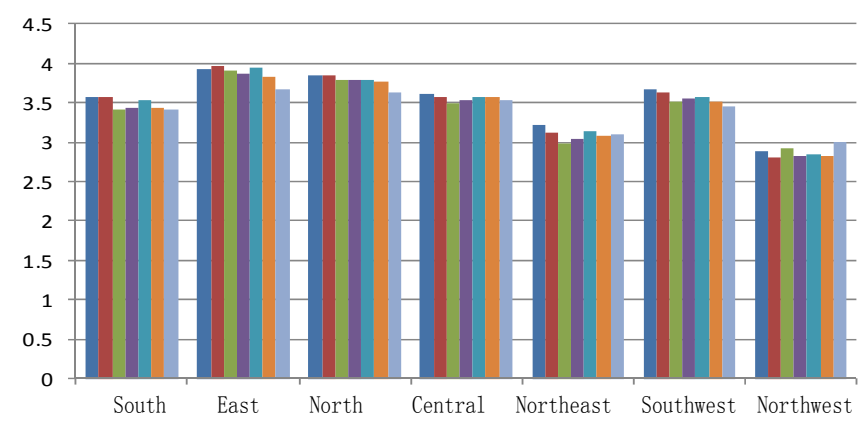

$$
\begin{aligned}
& \text { - Geography } \\
& \text { - Construction } \\
& \text { - Social } \\
& \text { - Legal } \\
& \text { - Economy } \\
& \text { - Management } \\
& \text { - Innovation }
\end{aligned}
$$

Figure 3. Regional factors that attracted Taiwan investment in Mainland China in 2010. Source: Based on the data gathered from Statistical Yearbook of Taiwan Economy 2010.

Studies of FDI in Mainland China have regarded the region as an independent factor without considering the effect of the spatial correlation between the FDI and its spatial distribution. Therefore, there are a few empirical analyses of the number of neighboring areas of FDI and the spatial effect on FDI production. Anselin, Rey and Montouri suggest that many regional economic phe-nomena are autocorrelated because of the effect of spatial continuity on regional distribution, which also applies to FDI. In recent years, the space dependence of regional economic growth has received increasing academic attention; the rapid development of spatial econometrics allows us to conduct empirical investigations of regional issues. Therefore, the use of spatial econometric models to examine the spatial distribution of non-equilibrium FDI will lead to more quantitative and accurate conclusions. This article will address questions regarding the spatial aspects of Taiwan investment in Mainland China and whether these aspects will affect the pattern of future Taiwan investment in Mainland China.

\section{Methodology}

\section{Economic Model}

1) Moran's I index

In order to identify the impacting factors of Taiwan enterprises' location strategy, we adopt spatial data model to examine the outcome. First, Moran's I Index is applied so as to find whether spatial heterogeneity does exist. Moran's I index has a significant advantage in the study of the relevance of spatial variables. It reflects the degree of similarity among the properties of the unit attribute values of adjacent regions to analyze the spatial autocorrelation coefficient between the variables. Moran's I index is calculated as follows where represents the regional observations, is the total number of regions, is the weight matrix for the adjacent space representing any of these elements. In general, the selection criterion is I which is in the range $-1 \leq \mathrm{I} \leq 1$. When the economic behavior of the two regions is positively correlated, I is positive. When the behavior is negatively correlated, I is negative. If $\mathrm{I}$ is 0 , the economies of these two regions are independent. The use of global and local Moran's I indices can reveal the spatial correlation of the overall region and the surrounding area.

The test of the regional spatial correlation is mainly based on testing of the maximum likelihood estimation hypothesis through Wald, LR and LM statistics, Moran's I spatial correlation index, and Geary C. However, Moran's I (Moran, 1948), LMerr (Burridge, 1980), LMsar, Lratios, Walds (Anselin, 1988), and other space-related tests proposed by single cross-section regression models cannot be directly used for a panel data model. In this article, we adopt Moran's I to measure the spatial distribution of Taiwan investment in Mainland China in the last 20 years, and we used the block-diagonal matrix $C=I_{T} \otimes W_{N}$ as a spatial weight matrix. These tests can be extended to panel data analysis.

2) The spatial panel data model

The spatial panel data model is generally divided into a spatial lag model and a spatial error model. LMerr and LMsar and their steady-form spatial correlation test can provide insight into the model setting and identify the selectivity of the spatial lag model and spatial error model. If LMsar (LMerr) is more significant than LMerr (LMsar), then the spatial lag model (spatial error model) is appropriate. This study obtained LMerr $(0.2144)>$ LMsar (0.0742) based on the outcome, thus, the spatial error model was more appropriate than the spatial lag model. Based on global spatial correlation, the spatial autoregressive model means that all explanatory variables of a region's economic growth act on other areas through a spatial transmission mechanism. The spatial error model shows that the impact of regional spillovers is the result of random shocks. Spatial error model (SEM) is as follows:

$$
\begin{gathered}
y=X^{\prime} \beta+\mu \\
\mu=\lambda\left(I_{T} \otimes W_{N}\right) \mu+\varepsilon
\end{gathered}
$$

Here, $y$ is the dependent variable, $X$ is the vector of the independent variables (including a constant term), $\beta$ is the variable coefficient, $\rho$ and $\lambda$ are spatial autore- 
gressive and spatial autocorrelation coefficients, respectively, and $\varepsilon$ is the error component. In the one-dimensional error decomposition model, $\varepsilon=\eta_{i}+v_{i t}$ or $\varepsilon=\delta_{t}+v_{i t}$; in the two-dimensional error decomposition model, $\varepsilon=\eta_{j}+\delta_{t}+v_{t i}, \quad \eta_{i} \sim I I D\left(0, \omega_{i}^{2}\right), \quad \delta_{t} \sim I I D\left(0, \xi_{t}^{2}\right)$ and $v_{t i} \sim \operatorname{IID}\left(0, \sigma_{t i}^{2}\right) \ldots t, i$ is the time dimension and cross-section dimension respectively. $I_{T}$ is the T-dimensional unit matrix, and $W_{N}$ is the spatial weight matrix $n \times n$ ( $n$ is the number of regions). The weight factor can be determined based on the actual situation.

This paper will use the spatial panel data to analyze Taiwan investment patterns in Mainland China. Therefore, we must select samples that contain measurement indicators. According to the geographical distribution of Taiwan investment in Mainland China published by the Investment Commission of the Taiwan Ministry of Economic Affairs, we selected 21 provinces in Mainland China that are autonomous regions as the statistical samples. They include Heilongjiang, Jilin, Liaoning, Hebei, Beijing, Shanxi, Tianjin, Shandong, Jiangsu, Anhui, Sichuan, Hubei, Chongqing, Shanghai, Zhejiang, Hunan, Jiangxi, Yunnan, Fujian, Guangdong, and Guangxi. The K-nearest neighbor (KNN) algorithm was used to estimate the Moran's I index test results, which are shown in Table 1.

According to the TEEMA report, the factors that affected Taiwan investment in Mainland China in 2008, 2009 and 2010 included twelve indices (see Table 1): geography, infrastructure, social environment, legal environment, economic environment, market environment, innovation environment, social risk, legal risk, operational risk, economic risk, and Taiwan appreciation degree which means the preference degree of Taiwan en-

Table 1. Regional impact factors of Taiwan investment in Mainland China.

\begin{tabular}{|c|c|c|}
\hline \multicolumn{2}{|c|}{ Independent variables } & \multirow{2}{*}{$\begin{array}{l}\text { Abbr. } \\
\text { ENVI }\end{array}$} \\
\hline \multirow{7}{*}{$\begin{array}{l}\text { Investment } \\
\text { environment }\end{array}$} & Geography & \\
\hline & Infrastructure & INFR \\
\hline & Social environment & SOEN \\
\hline & Legal environment & LAWE \\
\hline & Economic environment & ECEN \\
\hline & Market environment & MARK \\
\hline & Innovation environment & INEN \\
\hline \multirow{4}{*}{ Investment risk } & Social risk & SORI \\
\hline & Legal risk & LARI \\
\hline & Operational risk & MARI \\
\hline & Economic risk & ECRI \\
\hline $\begin{array}{c}\text { Taiwan appreciatic } \\
\text { degree }\end{array}$ & $\begin{array}{l}\text { legree of Taiwan preference for } \\
\text { investment in mainland }\end{array}$ & RECO \\
\hline
\end{tabular}

Source: Based on the data gathered from the TEEMA report. trepreneurs would like to recommend Mainland China to other Taiwan entrepreneurs as a investment regions. The data from the twelve indices in the samples in 2008, 2009 and 2010 included 2612 questionnaires, 2588 ones and 2618 ones, respectively. As the TEEMA report itself had corrected the statistical errors, we directly reported the TEEMA-published score values (between 0 and 5) as the independent variable data.

As the data presented in Table 2 were obtained by an independent evaluation of the sample data, and not the actual economic data, these variables should be independent. However, the data obtained from the multicollinearity test of the model had a high degree of correlation between these indices and multicollinearity. This trait might increase the standard error of the regression coefficients, thus changing the significance level and the direction of the regression coefficients. However, the collinearity of the econometric model would not affect the size of the regression coefficients. Therefore, we conducted a collinearity test to re-screen the independent variables. Significant regression coefficients may be obtained, but this would not help weigh the impact of the independent variables on Taiwan investment. Therefore, this article regards these twelve variables as independent.

3) Results analysis

a) Spatial agglomeration

Table 2. Moran's I index test for the provinces (1992-2010).

\begin{tabular}{ccccc}
\hline Time & Moran's I & $\mathrm{E}(\mathrm{I})$ & $\mathrm{Z}$ & $\mathrm{P}$ \\
\hline 1991 & 0.1848 & -0.0500 & 2.3133 & 0.0290 \\
1992 & 0.0518 & -0.0500 & 1.5217 & 0.0760 \\
1993 & 0.1336 & -0.0500 & 1.9165 & 0.0560 \\
1994 & 0.1663 & -0.0500 & 1.8711 & 0.0470 \\
1995 & 0.1531 & -0.0500 & 1.6580 & 0.0680 \\
1996 & 0.0992 & -0.0500 & 1.2300 & 0.0900 \\
1997 & 0.0836 & -0.0500 & 1.5321 & 0.0780 \\
1998 & 0.0519 & -0.0500 & 1.0922 & 0.1370 \\
1999 & 0.0167 & -0.0500 & 0.6624 & 0.2036 \\
2000 & 0.0064 & -0.0500 & 0.5465 & 0.2250 \\
2001 & 0.0762 & -0.0500 & 1.1951 & 0.1230 \\
2002 & 0.1675 & -0.0500 & 1.9454 & 0.0550 \\
2003 & 0.1228 & -0.0500 & 1.5897 & 0.0810 \\
2004 & 0.2012 & -0.0500 & 2.3281 & 0.0310 \\
2005 & 0.1659 & -0.0500 & 2.1419 & 0.0320 \\
2006 & 0.1166 & -0.0500 & 1.7463 & 0.0670 \\
2007 & 0.1216 & -0.0500 & 1.7386 & 0.0630 \\
2008 & 0.1417 & -0.0500 & 2.2606 & 0.0240 \\
2009 & 0.1300 & -0.0500 & 1.9956 & 0.0400 \\
2010 & 0.1012 & -0.0500 & 1.6154 & 0.0700 \\
\hline
\end{tabular}


Totally, data from 20 years of Taiwan regional investment in Mainland China show the characteristics of a positive spatial correlation. The data for 1991, 2004, 2005, 2008, and 2009 were significant at the 5\% level; 1993, 1994, 2002, 2006, and 2007 were significant at the $10 \%$ level. The positive correlation for the other years was not significant (see Table 2).

We choose 1991, 2005, and 2009 as three years with significant features of spatial concentration as well as adopting the year 2010 (the year ECFA was signed) to give four space location figures. Figure 4 shows that 1991 is the earliest year for which Taiwan investment statistics are available. The Pearl River Delta region has become the leading region of Taiwan investment. Fujian, Guangdong, and Shanghai are the three main investment areas and mostly represent labor-intensive industries. Taiwan investment in these three regions shows a positive correlation with space (first quadrant). Taiwan investment was low in the Guangxi, Jiangxi, Zhejiang regions, and the precise geo-spatial distributions were positively correlated to these three regions. Taiwan investment in the remaining provinces was relatively small. By 2005, the pattern of Taiwan investment in Mainland China had altered. There were significant positive spatial correlations between Jiangsu, Shanghai, Zhejiang, and Fujian. Guangdong, with a large amount of Taiwan investment, showed a negative correlation with the surrounding provinces and small Taiwan investment. Shandong, Anhui, and Guangxi had little Taiwan investment and presented a negative spatial correlation with neighboring countries. The remaining provinces that have low Taiwan investment showed a positive spatial correlation. In 2009, Jiangsu, Shanghai, and Zhejiang showed positive spatial characteristics. Shandong, Anhui, and Fujian presented a negative correlation. Guangdong, a province with heavy Taiwan investment, presented a negative correlation with the surrounding areas. However, Guangxi showed strong spatial independence. In 2010, the spatial heterogeneity of Taiwan investment in Mainland China was not significant, while the spatial distribution of Taiwan investment in Mainland China was homogeneous.

The LISA spatial concentration chart measured using the local Moran's I index shows (Figure 5) that the distribution of the 1991 Taiwan-invested region has two significant features. First, a significant positive correlation was indicated between low-low value areas in Sichuan (1\% level) and Yunnan (5\%). The spatial correlation of the remaining provinces was not significant. In 2005, Anhui Province and the surrounding areas showed a significant (1\%) negative correlation. Zhejiang and the neighboring regions showed a positive correlation at the $5 \%$ level. Sichuan and Yunnan showed a low positive correlation at the $5 \%$ level. The remaining provinces had no significant spatial correlation. In 2009, the provinces showing a low-low value positive correlation (5\%) were Yunnan, Sichuan, Hubei, and Chongqing. Anhui province showed a negative correlation at the 5\% level, and Zhejiang province showed $5 \%$ high-high value positive correlation. In 2010, Anhui province showed a low-high value negative correlation at the $5 \%$ level, while Zhejiang showed a high-high value positive correlation at the $5 \%$ level. The spatial correlation of the remaining provinces was not significant. Thus, Taiwan's investment in Mainland China over the past 20 years was the highest in Zhejiang Province, which had the strongest spatial correlation and the greatest homogeneity with the surrounding areas, while Anhui Province and its surrounding areas showed significant spatial heterogeneity. The pattern of Taiwan investment in Mainland China presents polarization and the lack of an appropriate inter-regional cooperation mechanism, which resulted in the weak spatial correlation between regions. The inter-regional distribution of Taiwan investment did not result in an interactive developmental situation.

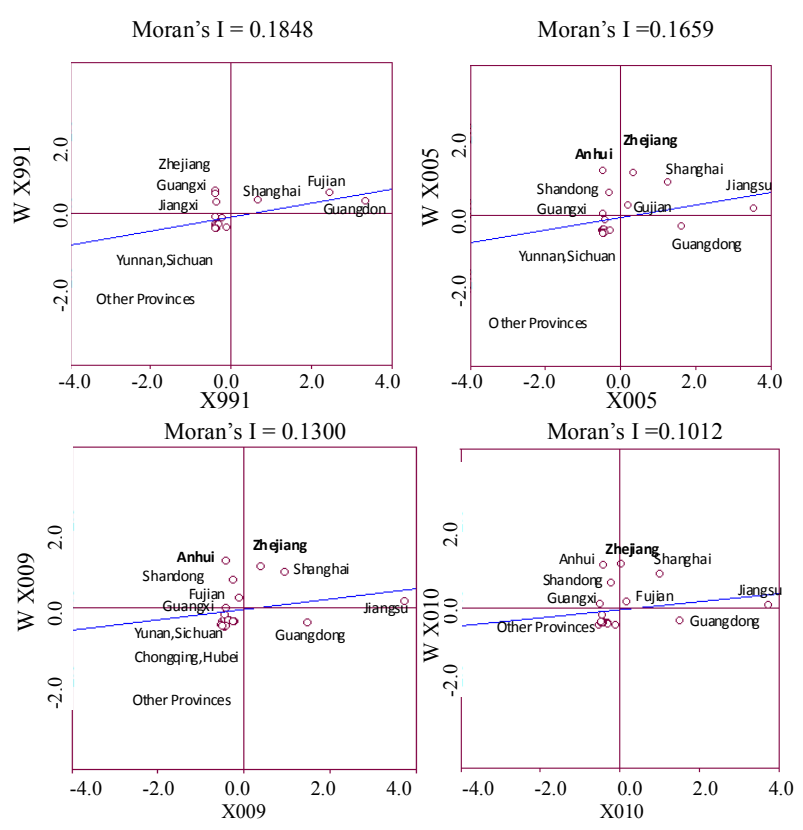

Figure 4. Spatial correlation charts of global Moran's I index.

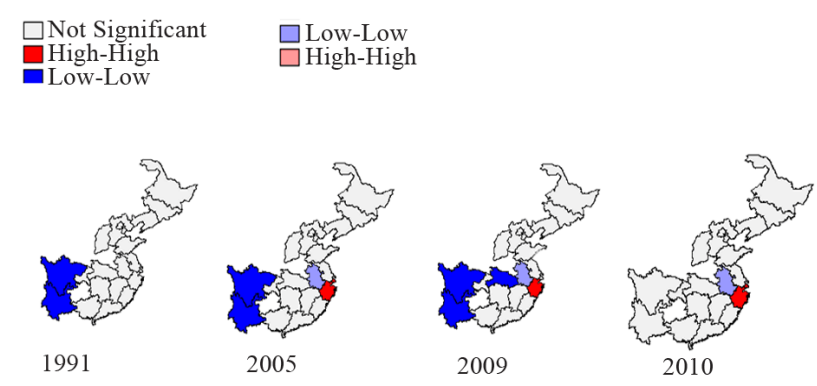

Figure 5. The spatial concentration of Moran's I index. 
The spatial correlation analysis shows that the regional distribution trajectories of Taiwan investment in Mainland China over the past 20 years have no significant continuous spatial correlation. The index of a year was selected to analyze the impact factors that affected Taiwan investment in Mainland China, regardless of the time factors. The key factors that truly affected Taiwan investment within a period of time could not be determined. Therefore, the longer the selected data sequence is, the more accurate the measurement results are. However, because the impact factors of Taiwan investment in Mainland China are complex, many indicators are difficult to quantify. Therefore, this paper selected the amount of Taiwan investment in Mainland China and the environment evaluation data describing Taiwan business investment in Mainland China released by the Taiwan Electrical and Electronic Manufacturers Association in 2008, 2009 and 2010, and we analyzed the impact factors based on data availability and index consistency. The three years were very meaningful. In 2008, when Taiwan's leader, Ma Ying-Jeou, took office, the cross-strait economic and trade exchanges improved. However, the 2009 global economic crisis seriously affected the exportoriented economic model used in Taiwan and caused a certain change in the cross-strait economic trade. In 2010, the global economy rebounded, the mainland economy rapidly stabilized, and the cross-strait countries signed an economic cooperation framework agreement (ECFA), which enhanced the confidence index of Taiwan enterprises to invest in the mainland. Whether it was macroeconomic indices in Taiwan or the cross-strait trade exchanges, a quick recovery was achieved.

b) Impact factors of the special agglomeration of Taiwan investment

First, the general spatial panel data were used for analysis. If the spatial correlation factors were not taken into account, the $\mathrm{F}$ test was significant $(0.0758>\mathrm{F} \alpha$ $(2,48)=5.79)$, and mixed effects models were established. To improve the impact of collinearity, we applied a two-stage cross-sectional regression weights model; the obtained results are presented in Table 3. The results show that regional differences were not taken into account, and the most important factors in Taiwan investment in Mainland China in the past three years are the improvement of the natural environment, infrastructure, and economic risk. The rest of the variables significantly affected Taiwan investment in Mainland China at the 5\% level. Among these factors, the social environment, the economic environment, and the market environment had significantly positive impacts. The legal environment and the innovation environment had significantly negative impacts. Social risk and market risk had significantly positive impacts on Taiwan investment. Legal risk had a significantly negative impact. The degree of Taiwan pre- ference had a significantly negative impact on Taiwan investment. It can be concluded from these results that the factors that effectively promoted Taiwan investment in Mainland China in the past 3 years mainly include the social environment, the economic environment, the market environment, and lower legal risk.

The mixed-effects model is appropriate for understanding the distribution of Taiwan investment in Mainland China because the model showed spatial characteristics as well as time features. Moreover, in 2008 and 2009, the global Moran's I index revealed that 21 Taiwan-funded investment regions had certain spatial correlations. Therefore, a geo-spatial correlation model was established for the tests. The SEM estimation results are shown in Table 4.

The results presented in Table 4 show that the 21 sampled areas receiving Taiwan investment in 2008, 2009 and 2010 had both space-fixed and time-fixed effects. The geographical environment and the market environment showed a significant positive relationship with Taiwan investment at the 1\% level; infrastructure and the legal environment showed a significant negative correlation at the $1 \%$ level; business risk and the degree of Taiwan entrepreneurs' appreciation showed a significant negative correlation at the $5 \%$ level.

The results of the spatial error model (SEM) showed that the difference in inter-regional geographical and market environments and the gradual improvement in

Table 3. Results of general panel model analysis.

\begin{tabular}{ccccc}
\hline Variable & Coefficient & Std. error & t-Statistic & Prob. \\
\hline ENVI & 0.437815 & 0.465588 & 0.940349 & 0.3472 \\
INFR & -1.134638 & 0.601653 & -1.885869 & 0.0595 \\
SOEN & 2.189960 & 0.485041 & 4.514996 & 0.0000 \\
LAWE & -6.714128 & 0.597710 & -11.23308 & 0.0000 \\
ECEN & 4.732710 & 0.400019 & 11.83122 & 0.0000 \\
MARK & 8.004338 & 0.634603 & 12.61315 & 0.0000 \\
INEN & -0.831210 & 0.417115 & -1.992758 & 0.0465 \\
SORI & 2.888208 & 0.534176 & 5.406851 & 0.0000 \\
LARI & -6.854205 & 0.750625 & -9.131328 & 0.0000 \\
MARI & 4.887199 & 0.805937 & 6.063994 & 0.0000 \\
ECRI & 0.001636 & 0.739322 & 0.002213 & 0.9982 \\
RECO & -3.817749 & 0.426538 & -8.950542 & 0.0000 \\
R-squared & 0.386220 & Mean dependent var & 11.79129 \\
Adjusted R-squared & 0.381071 & \multicolumn{2}{c}{ S.D. dependent var } & 1.806638 \\
S.E. of regression & 1.421319 & Sum squared resid & 2648.415 \\
Durbin-Watson stat & 1.393557 & Second-stage SSR & 2648.415 \\
Instrument rank & 13.000000 & & & \\
\hline & & & &
\end{tabular}


Table 4. Fixed effect spatial error model (SEM).

\begin{tabular}{ccccc}
\hline Variable & \multicolumn{4}{c}{ Coefficient } \\
\hline & Model 1 & Model 2 & Model 3 & Model 4 \\
\hline Intercept & 11.7995 & & & \\
ENVI & 1.3662 & $2.441638^{* * *}$ & 1.947974 & $2.946701^{* * *}$ \\
INFR & -2.1184 & $-4.711658^{* * *}$ & -2.075676 & $-5.252975^{* * *}$ \\
SOEN & 3.0410 & $1.912495^{*}$ & $3.760813^{*}$ & $1.856820^{*}$ \\
LAWE & $-7.4177^{* * *}$ & $-4.003429^{* * *}$ & $-8.309495^{* * *}$ & $-4.377563^{* * *}$ \\
ECEN & $4.5271^{* *}$ & 0.969862 & $4.874697^{* * *}$ & 0.843587 \\
MARK & $7.1753^{* *}$ & $4.465349^{* * *}$ & $6.916222^{* *}$ & $5.001891^{* * *}$ \\
INEN & -1.2589 & $-2.188730^{* *}$ & -1.527832 & $-2.250578^{* *}$ \\
SORI & 1.7089 & 0.783276 & 1.417288 & 1.431297 \\
LARI & $-6.6332^{* *}$ & -0.882737 & $-7.455075^{* *}$ & -0.703268 \\
MARI & 3.3069 & $-4.182716^{*}$ & 3.404127 & $-5.666034^{* *}$ \\
ECRI & 0.6318 & 1.579397 & 1.568447 & 2.009705 \\
RECO & $-4.4494^{* *}$ & $-1.883895^{* *}$ & $-4.853772^{* *}$ & $-2.048145^{* *}$ \\
Spat.aut. & -0.1790 & -0.210969 & $-0.233976^{*}$ & $-0.312971^{* *}$ \\
R & 0.4145 & 0.9296 & 0.4075 & 0.9289 \\
F & -110.08523 & -43.476101 & -110.68627 & -44.30271 \\
Total time & 0.4810 & 0.1220 & 0.0970 & 0.1140 \\
\hline
\end{tabular}

Note: ${ }^{*} \mathrm{p}<0.1 ;{ }^{* *} \mathrm{p}<0.05 ;{ }^{* * *} \mathrm{p}<0.01$. Model 1: No fixed effects; Model 2: Spatial fixed effects; Model 3: Time-fixed effects; Model 4: Spatial and time-fixed effects.

each region of these two factors had a significant positive impact on Taiwan investment in Mainland China over the past three years. The difference in the inter-regional infrastructure and the legal environment significantly restricted the Taiwan regional investment strategy. The results of Model 4 indicate that business risks and the degree of Taiwan entrepreneurs' appreciation more significantly $(5 \%$ level) restricted the choice strategy of Taiwan investment in Mainland China. If regional differences were not taken into account, of the most important factors regarding Taiwan investment in Mainland China in the past three years, the social environment, the economic environment, the market environment, social risk and market risk had significantly positive impacts. The legal environment, the innovation environment, legal risk and the degree of Taiwan entrepreneurs' appreciation had significant negative impacts on Taiwan investment.

\section{Conclusions and Policy Implications}

This paper highlights the spatial agglomeration and impacting factors of Taiwan enterprises investment in Mainland China. When compared with the overall effect that did not take regional and time factors into account, regional differences and time factors had significant impacts on Taiwan investment in the mainland.

First, Taiwan investment in Mainland China and business risk are negatively correlated, indicating that Taiwan investment in Mainland China was affected by the overall cross-strait economic relations, especially in Taiwan in recent years. Taiwan's major political events affected the desirability of Taiwan investment in the mainland, and the nationalist party returned to power after 5.20 of 2010, which gradually reduced the positive message that was conducive to the cross-strait economic interaction. It also affected and changed the confidence, behavioral strategies and regional distribution of Taiwan investment in Mainland China. Thus, the low-risk business region was more attractive to Taiwan companies.

Second, there was a significant positive correlation between the geographical environment and the market environment and Taiwan investment in Mainland China, indicating that the investment motivation of Taiwan businesses over the past 20 years has gradually changed from cost-driven to market-oriented and environmentoriented motives. Thus, when the market environment of a region was favorable and the geographical environment was also adapted to the development of Taiwan business, this area was likely to grow into a Taiwan investment gathering area. However, one drawback was that region's infrastructure and legal environment show a significant negative correlation with Taiwan investment in the mainland. One possible explanation is that the scoring of these independent variables of Taiwan enterprise was based on the combined results of the last year's overall evaluation and this year's forecasts ${ }^{1}$. Thus, Taiwan investment in Mainland China was motivated by faith in the quality of the mainland regional infrastructure and legal environment in the last year and in its improvement in the coming year. In fact, Taiwan investment in Mainland China showed a negative correlation with the geographical environment and market environment.

Third, we would like to assume that Taiwan entrepreneurs' appreciation and the amount of Taiwan investment would be positively correlated, but our results are the opposite. We believe that the main reason was that more information about Taiwan enterprises invested in the mainland in the past three years was provided from the rational investment decisions and market research, which had changed the original "rooted network" Taiwan-funded enterprises' developmental pattern and had gradually changed to an open style of co-investment. Therefore, Taiwan investment increased in only a few situations through Taiwan entrepreneurs' appreciation. At the same time, because the degree of Taiwan recommendation was

${ }^{1}$ Because the TEEMA report is published in August each year, the evaluation score includes both a comprehensive evaluation of the performance of the previous year and a current year forecast. 
the combined evaluation of the effect of Taiwan investment in Mainland China over the last year and the comprehensive evaluated value of this year's forecasts, it is possible that the larger the Taiwan investment amount was, the lower the Taiwan recommendation because Taiwan entrepreneurs believed that investment in a Taiwan gathering area (investments in some areas were close to saturation) would offer less flexibility for business growth. The businesses have difficulty obtaining sufficient social capital for their development (such as reputation, government support, social network); there may even be rigorous competition. Therefore, the degree of Taiwan entrepreneurs' appreciation and the amount of Taiwan investment are negatively correlated.

Overall, based on the performance of Taiwan investment in Mainland China in the last three years, Taiwan-funded enterprises paid more attention to the optimal environment to develop the best regional investment strategy. Taiwan's investment motive was more comprehensive and objective, which challenges the mentality that Taiwan investment in Mainland China is based on the lowest operating cost 20 years ago, taking the ideas of "human networking" and "just having a try" to invest. The increased investment was the result of emotional judgments and subjective selection. Therefore, the overall pattern of Taiwan enterprise investment in Mainland China is changing.

From spatial correlation analysis and the spatial panel data analysis of Taiwan investment in Mainland China in the past three years, the pattern of the Taiwan-funded enterprises in the mainland area shows a certain spatial correlation. In three typical years, 2008, 2009 and 2010, time-fixed effects were evident in the pattern of Taiwan investment in Mainland China. The regional distribution of Taiwan investment in Mainland China shows the individual characteristics of specific years and regions. In this situation, the future investment distribution of Taiwan enterprise in the mainland could not be macroscopically based on the changes of the overall investment environment in the mainland. Instead, future Taiwan investment distribution should start with different regions and carry out regional distribution with focus.

1) The spatial heterogeneity of the regional distribution of the Taiwan investment in the mainland increased; thus, the combination of investment factors should be considered based on the characteristics of different regions.

The regional economic development potential and the regions with good basic conditions better attracted Taiwan investment, which was particularly evident in the eastern coastal areas (Jiangsu). Factors such as infrastructure, legal risk, and social risk decreased the willingness of Taiwan entrepreneurs to invest in the mainland. Therefore, each region can attract Taiwan investment from such angles as improving the region's infrastructure environment and reducing the legal risk, market risk, and social risk.

At the same time, Taiwan investment in Mainland China over a longer period of time showed characteristics of gradual accumulation. The individual provinces indicated a clear spatial autocorrelation, but the provinces that received Taiwan investment did not show overall spatial dependence. The spatial distribution of Taiwan investment in the mainland showed an obvious polarization effect. In attracting Taiwan investors, interregional competition is stronger than inter-regional cooperation. The continuation of this situation is not conducive to a balanced pattern of Taiwan investment in Mainland China. If only from the overall study to affect the factors of Taiwan investment in the mainland, ignoring the factors of regional investment differences, this situation may expand the distribution characteristics. Therefore, future Taiwan-funded enterprises need to consider in detail the specific factors that affect the future development of Taiwan investment from the district level; various regions also need to develop differentiation strategies to attract foreign capital based on its own natural resources and storage and space development.

2) The time effect of the spatial distribution of Taiwan investment in Mainland China gradually increases; therefore, rational methods should be used to develop investment strategies.

Twenty years of investment data show that changes in cross-strait relations are an important factor in Taiwan investment in Mainland China. The pattern of Taiwan investment in Mainland China shows clear time-fixed effects. However, if the space-fixed effects are combined, we find that Taiwan investment in Mainland China is no longer solely the result of perceptual judgments of regional distribution; instead, rational, objective investment factors affect Taiwan. Recent years have been marked by improved openness of the global investment environment, increased popularity of the information network platform, expansion of communication channels, and changes in investment philosophy. A company's outside investment is not only a purely economic behavior; it has slowly evolved into a fusion behavior of psychology, information, systems, and policies. Therefore, it is only dependent on the investment of "lowest cost" or "acquaintances", and investment does not seem to have become less important. It is supplemented by more factors from the investor's perspective and gradually affects the investor's success. In this regard, the spatial distribution of Taiwan investment in Mainland China relies on long-term, cumulative study of the changes in the investment environment to scientifically and rationally develop investment strategies; it is not possible to immediately develop regional investment strategies. 
3) In addition to the supply of the regional elements, Taiwan investment in Mainland China also needs to consider the industrial areas that match the regional elements.

Currently, Taiwan's leading investment in the mainland is in the electronics and information industry; other high-end manufacturing and modern service industries are not significant. Therefore, in this study, some significant indices that affect Taiwan's investment in the mainland are important for the manufacturing industry, especially the electronic information manufacturing industry. Nevertheless, these indicators may not affect the future of the factors of the Taiwan business pattern. If more Taiwan investment in Mainland China goes to the service industry or other areas of the manufacturing industry, perhaps the regions that do not have significant spatial characteristics will become evident.

After ECFA, an important aspect of the cross-strait industrial negotiation is the possible areas and mechanisms of industrial cooperation. In this context, Taiwan entrepreneurs can consider whether the supply of the environmental factors of an area meets the needs of the overall Taiwan business at this stage, convert the industry to its own operation, and choose to invest in the industrial areas that match the regional elements, or a business can invest in different areas. For example, in the absence of an environmental support platform, but with the advantage of the region of the upstream manufacturing industry, Taiwan investment may consider introduceing production services (such as $\mathrm{R} \& \mathrm{D}$ center, testing center, and financial platform) in the areas of developed service, rich capital. However, the technological innovation capacity needs to be improved, extending the manufacturing industry and requiring it to swim upstream to R \& $\mathrm{D}$ and downstream to market development and brand development areas.

4) Regions must start by improving the conditions of employment, increasing the education level, strengthening the legal system, and enhancing regional industry chain integrity to start attracting Taiwan investment.

Currently, the regional governments of the mainland are concerned about the development of Taiwan investment. However, the unavoidable regional differences present a natural barrier, which leads to spatial heterogeneity of Taiwan businesses in Mainland China. In this situation, each region should start with its own specific characteristics to improve the investment environment conditions and accumulate the stock elements. However, as a whole, the employment environment, education level, legal conditions, and the integrity of the industry chain of any one region will have a long-term impact on FDI. These factors and conditions cannot be changed overnight. They must be addressed early and persistently. From an economic sense, the improvement of these elements is a process of increasing returns to scale. The re- turns may not be seen at the beginning of the investment, but with the increase in the stock investment, the effect will appear gradually.

In this regard, the construction of local job market through improvement of the educational institutions to enhance the level of human capital stock, increasing efforts to create a safe and legal environment for business, and assembly of a complete upstream and downstream industry chain, which will fundamentally change the embarrassing situation of "hard labor, lack of talent, fear for infringement, less foreign aid", will increase the chances of success for the regions that attract Taiwan investors.

In cross-strait industrial cooperation, the pattern of Taiwan investment in Mainland China has shown a certain degree of heterogeneity and spatial dependence that is not strong, yet is doubly affected by time and spatial effects. The national "ten two five" plan aimed to "strengthen and improve inter-regional cooperation mechanism, remove market barriers to promote factors mobility, and guide the orderly transfer of industry", which emphasizes regional cooperation. Furthermore, the concept of coordinative development has become the primary regional guiding strategy in the current economic map of Mainland China. Therefore, this strategic thinking should be integrated into the pattern of Taiwan investment in the mainland, and focus should be placed on improving the quality of Taiwan investment, balancing the proportion of Taiwan-funded regions and emphasizing cooperation to avoid the competition and rent-seeking of different areas that attract Taiwan investment. This information will be important after the subsequent implementation of the cross-strait economic cooperation framework agreement (ECFA), which is also an important mechanism for promoting cross-strait industrial cooperation.

\section{REFERENCES}

[1] X. J. Zou, "The Historical Analysis of 1979-2000 Taiwan Investment in Mainland China," Information Economics and Law, Vol. 24, No. 3, 2005, pp. 30-35.

[2] M. C. Yu, "The Effect of Mainland Employment of Taiwan Investment in Mainland China-Based on the Empirical Analysis of Panel Data from Seven Provinces and Municipalities," International Trade and Economy Exploration, Vol. 18, No. 8, 2008, pp. 62-66.

[3] P. X. Nie, "New Situation and Countermeasures of Taiwan Investment in Mainland," International Economic Cooperation, Vol. 25, No. 9, 2009, pp. 32-35.

[4] A. Yan, "The Economic and Political Research of Taiwan Investment in Mainland China-The Reformation, Opening up and Modernization of the Mainland and Taiwan Compatriots in Three Decades," Chinese Communist Historic Research, Vol. 22, No. 1, 2011, pp. 53-69.

[5] X. M. Duan, "A Comparative Analysis of Mainland ChinaBased Taiwan Investment Environment," World Economics, Vol. 25, No. 2, 2006, pp. 71-81. 
[6] S. G. Dai and P. S. Dai, "The Factor Analysis of the Spatial Correlation of Taiwan Investment in Mainland Areas," Taiwan Research Bulletin, Vol. 28, No. 4, 2008, pp. 4855.

[7] Z. Wang and Y. X. Wang, "The Integration Study of Taiwan-Funded Enterprise in Mainland China Business Economic Issues," Vol. 31, No. 4, 2009, pp. 56-58.

[8] S. D. Hu, "The Choice of Regional Institutional Environment and the Location of Taiwan Investment in Mainland China," Taiwan Research Bulletin, Vol. 28, No. 5, 2010, pp. 64-72.

[9] S. G. Dai and W. H. Ceng, "The Performance Comparison of Taiwan Investment in Mainland China Gathering Area and Taiwan Areas Economic and Trade CooperationEmpirical Research Based on the DEA-Tobit Method," International Trade Issues, Vol. 37, No. 3, 2011, pp. 167176.

[10] J. Y. Sheng, "The Impact of Taiwan High-Tech Industry Investment in the Local Industrial Chain Formation in Yangtze River Delta," Straits Technology and Industry, Vol. 21, No. 1, 2008, pp. 24-27.

[11] G. Q. Cheng and L. Z. Chen, "The Study of the Development of Taiwan Entrepreneurs Direct Investment in Jiangsu Study," SAR Economy, Vol. 28, No. 12, 2010, pp. 5758.

[12] F. Li, "Review and Policy Ideas of the Development of Taiwan Investment in Fujian," Fujian Normal University (Social Science Edition), Fuzhou, 2010.

[13] F. J. Wu and F. Li, "The Location Differentiation and the Cause Analysis of Taiwan Entrepreneurs's Direct Invest- ment in Agriculture in the Mainland," Agricultural Economy, Vol. 31, No. 11, 2011, pp. 73-79.

[14] W. Jiang, "The Dynamics and Influencing Factors of Taiwan Investment in Shenzhen," Reform and Strategic, Vol. 23, No. 1, 2007, pp. 100-103.

[15] Y. L. Wang and J. Wang, "The Focus Shift of Taiwan Investment in Mainland China: Stages, Characteristics and Influencing Factors," Southeast Academic, Vol. 23, No. 2, 2010, pp. 61-69.

[16] X. M. Duan and Z. Y. Zhang, "Substitute or a Complement: A Dynamic Analysis of Taiwan Investment and the Cross-Strait Trade," World Economic Research, Vol. 30 No. 2, 2011, pp. 80-86.

[17] Y. B. Zhang, "The Location Choice Model and the Concentration Study of Direct Foreign Investment," Ph.D. Thesis, Northeastern University, Shenyang, 2008.

[18] S. J. Chang and S. Park, "Types of Firms Generating Network Externalities and MNS's Co-Location Decisions," Strategic Management Journal, Vol. 26, No. 7, 2005, pp. 595-615. doi:10.1002/smj.464

[19] X. H. Kang and W. Z. Liao, "The Empirical Research That Affects the Amount of Taiwan Investment in Mainland China and Factors of Investment Location," Jiaotong University Journal of Management, Vol. 26, No. 1, 2006, pp. $15-23$.

[20] W. H. Davidson, "The Location of Foreign Direct Investment Activity: Country Characteristics and Experience Effects," Journal of International Business Studies, Vol. 11, No. 2, 1980, pp. 9-22. doi:10.1057/palgrave.jibs.8490602 